\title{
algumas consideraciones sobre la investigación de desarrollo
}

\author{
Conferencia pronunciada por D. Jaime NADAL, \\ Director del Instituto Eduardo Torroja. \\ en las Sesiones Plenarias del Patronato de Investigación Científica y Técnica
}

EXCMOS. SENORES, SENORAS, SEÑORES:

Ante el auditorio más calificado de España, me invitan a desarrollar esta ponencia que trata de un tema al que habéis dedicado todos muchas horas de meditación. Un tema sobre el que cada uno de vosotros ha procúrado acumular cuanta información le ha sido posible y, en definitiva, una materia de la que sois verdaderos maestros.

Cuanto os diga resultará de sobra conocido y me temo no poder aportar ni un ápice de nuevo interés. Ni una brizna de originalidad.

Sin embargo, voy a intentarlo, y para ello entiendo que es conveniente dejar a un lado las citas eruditas, olvidar por unos momentos los planteamientos clásicos y entrar, sin más, a ocuparnos de la

\section{Investigación de desarrollo}

definida como la búsqueda de técnicas, tecnología y "know-how» directamente aplicables a la creación de nuevos productos, de nuevos servicios o a la mejora y abaratamiento de los productos o de los servicios existentes.

En definitiva, vamos a centrarnos sobre la rama de la investigación técnica que más contribuye a mantener la competitividad en el mercado y muy especialmente en el mercado internacional.

\section{El comercio de téenieas}

En este tipo de investigación no es concebible partir de cero, ni siquiera de un nivel tan bajo que destaque fuertemente de los 
niveles de servicio que configuran la producción actual en los países más avanzados.

Por consiguiente, el lanzamiento exige, como fase previa, la incorporación de técnicas ajenas. De todas las formas posibles, y aún podríamos decir que usuales, de adquisición de técnicas, vamos a considerar sólo una de ellas: LA COMPRA.

Esto nos conduce a la necesidad de centrar nuestra atención en la importante cuestión del comercio de técnicas cuya liberalización consideramos paso previo a cualquier liberalización del comercio de productos.

A este respecto, quisiera aclarar que nos estamos refiriendo a la adquisición de técnica y no a un comercio donde lo que realmente se compra es el prestigio de tal o cual firma extranjera para utilizarlo con fines exclusivamente comerciales.

Este comercio, en gran parte basado en un papanatismo carpetobetónico, es vicioso y no conduce más que a encarecer los productos. Sobre todo, si como ocurre con frecuencia, se importa una técnica para no utilizar más que su nombre.

Los centros de investigación de carácter estatal podrían tal vez tomar sobre sí la tarea de informar a quien proceda, si la técnica que se importa es realmente utilizada o si se trata simplemente de una maniobra de carácter publicitario, en cuyo caso se podrían economizar las correspondientes divisas, en beneficio de todos.

En relación con este comercio de técnicas, o si preferís de resultados de investigación de desarrollo, entendemos que es tanto más beneficioso cuanto más desarrollado esté y cuanto mayor volumen alcance, siempre que se mantenga equilibrada la balanza de importaciones y exportaciones, ni más ni menos que como ocurre en cualquier otra rama del comercio internacional. No olvidemos que los Estados Unidos es la nación que más técnica exporta, pero es también la que más técnica compra. Este y otros grandes clientes permiten establecer en los diversos países criterios selectivos para ir delimitando campos preferentes en los que la propia investigación puede alcanzar niveles exportables, bien en forma de patentes, de "know-how» o de ingeniería.

Los centros oficiales apenas si tienen posibilidades en cuanto a la realización de Investigación de Desarrollo, propiamente dicha. Sin embargo, entendemos pueden constituir soporte esencial de la misma, si orientan y acompasan sus investigaciones de carácter técnico a las necesidades concretas de la industria privada. Con esto venimos a insistir, una vez más, en la necesidad de un mayor entendimiento con la industria y los industriales, según esquemas ágiles y operantes que, al parecer, ni unos ni otros acertamos a plantear. 
Otro aspecto del intercambio de investigación y de técnica, lo constituye la selección de técnicas a adquirir por la industria, lo cual no es tarea fácil.

No podría asegurar que en todos los casos nuestros Centros de Investigación estén en condiciones de prestar un asesoramiento eficaz a la hora de importar técnica de desarrollo, pero de lo que sí estoy firmemente convencido es de que pueden contribuir mucho a dar a conocer a los importadores todos los aspectos de las técnicas y "know-how" que han adquirido. Nos consta que, con frecuencia, algunos de nuestros industriales importan investigación de desarrollo y carecen de los equipos adecuados para aplicarla y sacar todo el partido posible de lo que adquieren, con lo que de su importación se aprovecha sólo una mínima parte.

En relación con esto, parece claro que los Centros de Investigación oficiales podrían configurar dos líneas de acción:

- La primera consiste en algún género de asesoramiento al industrial respecto de la totalidad de posibilidades que le proporciona la técnica o el asesoramiento que acaba de importar.

- La segunda podría consistir en que dichos industriales cedieran a los Centros de Investigación los aspectos marginales de sus técnicas importadas, para que debidamente clasificadas y puestas a punto pudieran servir de base de partida a nuevas investigaciones, e incluso pudieran adaptarse a otras industrias.

En todo caso cabe admitir que nos corresponde a nosotros sugerir alguna acción tendiente a limitar el despilfarro de técnica importada, exigiendo que las entidades importadoras cuenten por lo menos con equipos técnicos suficientemente numerosos y bien dotados como para "ENTERARSE» de lo que compran y para aprovechar una parte apreciable de la misma, cosa que me temo no se cumpla ahora con excesiva frecuencia.

\section{Características}

La Investigación de Desarrollo, a diferencia de la Investigación Básica, es eminentemente concreta y determinada, basánđose esencialmente en principios científicos de dominio general e incluso en los resultados, también conocidos, de una investigación técnica de amplio espectro.

La investigación de desarrollo ofrece al investigador el mínimo de libertad, hasta el punto de que en ella no se concibe el trabajo "sobre tema libre", cosa que al sentir de muchos constituye un atentado intolerable al derecho de libertad creadora que debe tener todo hombre de ciencia. 
En esta modalidad no es admisible el profundizar en un tema por pura especulación y le está vedada la DILECTANCIA.

La "DILECTANCIA» es a la investigación algo así como la "REDUNDANCIA" al lenguaje. En esencia, aporta tan poca información que puede considerarse como algo perdido e inútil. Sin embargo un idioma sin "redundancias» estaría desprovisto de posibilidades poéticas y, por lo tanto, sería fatigoso de entender y difícilmente asimilable, porque impondría la necesidad de una atención ininterrumpidamente mantenida. Pues bien, analógicamente, la total ausencia de "dilectancia» hace fatigosa la investigación por hipertrofia de su "finalismo», lo cual he observado que contraría profundamente a nuestros investigadores, especialmente a los que en su formación predomina la vertiente científica sobre la vertiente técnica y aún dentro de éstos últimos resulta particularmente incómodo para los que no cuentan con experiencia industrial.

De todo esto se infiere que por propia NATURALEZA la Investigación de Desarrollo tiende a ubicarse en la empresa, despegándola de los centros de investigación de ámbito más amplio. Incluso de los Centros de Investigación Técnica de carácter sectorial.

Por otro lado, resulta que la Investigación de Desarrollo es tal vez la que precisa de mayor dosis de pragmatismo y una mayor servidumbre a los medios materiales de la producción industrial en marcha, de tal manera que la experiencia del equipo cuenta tanto como su preparación teórica y la trayectoria evolutiva de los métodos pesa tanto como la intuición o la imaginación de sus componentes.

Además, esta rama de la investigación no puede centrarse más que en actividades que en un momento dado sean o puedan ser razonablemente competitivas, sobre todo actividades que cuentan ya, en el momento inicial de su despegue, con un volumen importante de producción. Esto abunda en el carácter preponderantemente empresarial de esta investigación.

Finalmente, la Investigación de Desarrollo es, en general, la que precisa de más medios materiales, es decir, la de producción más costosa, si bien, en contrapartida, podemos decir que de hecho es la única comercializable y que sus precios en el mercado son altísimos, de tal suerte que para muchas empresas supone importante fuente de ingresos la venta de técnica actual e incluso la venta de lo que pudiéramos calificar de "chatarra», porque la técnica de punta, la técnica del mañana, objetivo primordial de la Investigación de Desarrollo, no sale nunca al mercado como producto de compraventa. La técnica del mañana permanece guardada y en el más riguroso secreto y se cede únicamente por vía de intercambio o por vía de coproducción, como es el caso de los últimos avances en materia de semiconductores de silicio. 
Aunque sólo sea por esa razón, es forzoso incorporarse en mayor o menor grado al esfuerzo general que el mundo a que pertenecemos está realizando en orden a estas actividades, pues de otro modo jamás tendremos acceso a las técnicas más modernas $\mathrm{y}$, por lo tanto, nunca podremos exportar tecnologías apreciadas.

\section{Amplitud}

El resultado de la Investigación de Desarrollo es aplicable a todo el producto nacional, tanto al SECTOR PRIMARIO como a la INDUSTRIA y a los SERVICIOS.

El impacto de la Investigación de Desarrollo sobre este producto nacional, considerado en su conjunto, depende:

a) Del ambiente o clima general.

b) Del estímulo, tanto de la empresa como del investigador.

c) De le inversión material empleada en su producción.

d) De la productividad de la organización en que tiene lugar esta investigación.

e) De las técnicas aplicadas que son, a su vez, el resultado de esta investigación.

A nivel nacional, la creación y el fomento del clima adecuado es una cuestión de gobierno, ligada a la política industrial del país. El soporte más firme de esta política, en lo que a la permeabilidad de la gente se refiere, ha sido tradicionalmente el desarrollo militar y, en el último extremo, la guerra. Hoy, afortunadamente, parece que puede canalizarse el interés popular a través de empresas nacionales de carácter "cuasi deportivo" y de enunciado simple e inteligible. Hasta ahora el que parece dar mejores resultados es La Conquista del Espacio y, en términos más concretos, la carrera a la Luna, que ha permitido poner a punto tecnologías que, sin este motivo, hubieran tardado muchos años en desarrollarse.

El acierto de señalar como objetivo LA LUNA ha sido indudable, por el hecho de que ha sido comprendido por todos y porque todos se consideran ligados a la empresa. Esta carrera a la Luna da lugar a un gran número de objetivos parciales que abarcan un amplio campo de la producción, con lo que se han puesto en marcha innumerables equipos de investigación, lo que ha obligado, a su vez, a desarrollar una sistemática de la investigación y una técnica de coordinación que han permitido esa concentración jamás igualada sobre unos determinados objetivos. Esta densidad y sincronismo está dando en América, Rusia y Japón una fuerza extraordinaria y creciente. Sin embargo, Europa ha quedado, en general, algo retrasada en este movimiento y a ello se

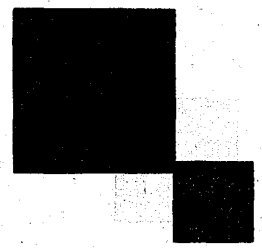


debe ese "gap" tecnológico que aparece en varios campos de la producción europea y que hasta el momento actual no parece que se haya podido compensar.

En cierto modo, la concentración de esfuerzos sobre temas de ámbito muy reducido tiene cierta semejanza ideológica con el LASER (*) o el MASER. Podríamos denominarlo, humorísticamente, RASER (**) Research, Amplification, etc., etc.) que ofrece posibilidades más importantes en la Investigación de Desarrollo que en ninguna otra y abre a la investigación que se centra en el Patronato un portillo que puede ser interesante.

A ello volveremos al final de estas líneas.

El estímulo para esta investigación, hoy por hoy, parece tener una raíz fundamentalmente comercial y sólo puede encontrarse en la gran empresa donde confluyen el interés de la expansión y los medios para impulsarla.

El Estado puede contribuir al estímulo y crear motivaciones con el arma económica que hoy por hoy es lo que produce mayores efectos.

Sugerimos:

1. La compra de investigaciones por parte del Estado, anunciando concursos a través de encargos concretos. (Entendemos que por este camino podríamos llegar más lejos que por el de las subvenciones a fondo perdido.)

2. Exigir y sancionar con el correspondiente gravamen fiscal que las empresas importadoras de técnica cuenten con la base apropiada para «enterarse y aplicar» toda la técnica que adquieran.

En este orden de ideas parece razonable exigir a las empresas que por cada veinte millones de técnica importada cuenten, al menos, con un equipo de diez especialistas dedicados a enterarse y a aplicar convenientemente los nuevos métodos.

3. Encarecer con impuestos determinadas importaciones de técnica y favorecer otras.

4. Favorecer las posibilidades de exportación de nuestras técnicas a través de la ingeniería o a través de productos terminados e incluso a través de licencias.

(*) LASER: Light Amplification by Stimulated Emission of Radiation.

(*) Se trata simplemente de una sugerencia a efectos expositivos. No confundir con el verdadero significado de RASER (longitud de onda para radiofrecuencia). 
5. Participar en la designación de objetivos para la Investigación de Desarrollo y comprobar la calidad y fiabilidad de los resultados.

\section{Programación}

Las grandes empresas, que es donde hoy se realiza la mayor parte de la Investigación de Desarrollo, actúan por lo que se llaman "CASOS».

A cada "CASO DE DESARROLLO» se le da una preferencia y se le señala un objetivo muy definido y muy concreto. Luego se calcula el plazo, se le atribuyen unos medios humanos y materiales y se le fija un coste total. A veces, según la dificultad de alcanzar el objetivo marcado, se atribuye una probabilidad de resultados positivos, y cuando el «CASO» es difícil y, por lo tanto, la probabilidad es baja, se emprende simultáneamente por varios equipos independientes.

Sólo con esta sistemática ha sido posible resolver en plazo razonable los innumerables problemas que se han presentado en el gigantesco esfuerzo de la conquista del espacio; pero sin ella, bien es verdad, que un fabricante de electrodomésticos puede verse el mejor día eliminado del mercado.

Por consiguiente, en la Investigación de Desarrollo es fundamental el acierto al señalar los objetivos y muy importante la planificación de las operaciones, captando la verdadera dimensión de los escollos a salvar y arbitrando los medios materiales que hayan de ponerse a contribución del empeño.

El investigador ha de seguir paso a paso en su actuación la programación establecida con una mentalidad específica y un orden riguroso en su trabajo, obteniendo dentro de los plazos previstos los resultados parciales que precisan los otros miembros del equipo para seguir conjuntados.

Reconozcamos que esta sistemática cuadra mejor en un ambiente sajón, pongo por caso, que en una mentalidad latina.

La lógica, pesa aquí más que la imaginación, y como es precisa mucha información, resulta que su tratamiento adecuado cae rápidamente del lado de la mecanización.

Con todo esto y con la necesidad de ir cumpliendo etapas intermedias acordes con un plan que debe seguirse con cierta rigidez y que involucra incluso los costes de producción, se llega a una productividad enorme a cambio de la rara sensación de sentirse eslabón en un mecanismo, lo que puede llegar a ser deprimente si falla el estímulo, y el estímulo, en última instancia, radica en el acierto con que se fijará el objetivo. 
Por lo tanto, para desencadenar acciones en la línea de la Investigación de Desarrollo, se necesita ante todo contar con experiencia en la programación de este tipo de investigaciones, y esto, a su vez, se obtiene mediante la investigación sobre el tema de la programación. Diríamos que es la investigación de la Investigación, aspecto éste que entiendo merece la pena consideremos la posibilidad de iniciarlo en el seno del Patronato.

Por lo tanto, me permito sugerir que a título de tentativa, puramente exploratoria, se fijará en el Patronato un par de «CASOS DE DESARROLLO», en cada uno de los cuales pudiéramos actuar varios Institutos. Sugiero también que señalemos con precisión los objetivos a cumplir. Que se planifique, a nivel general, y que dentro de cada Instituto se programe al nivel parcial que le correspondiera y que luego actuemos por vía de concentración «RASER» los diversos equipos. Creo sinceramente que la experiencia podría tener interés. Creo que merece la pena que lo intentemos, para comprobar:

1. Si somos capaces de crear motivación suficiente en las fuerzas susceptibles para desencadenar investigación.

2. Para empezar a poner a punto una técnica de coordinación de equipos de investigación y concentración de esfuerzos.

3. Explorar nuestras propias posibilidades en orden a crear tecnología de primera calidad.

4. Empezar a ir adquiriendo conocimientos que nos permitan en su día seleccionar los Campos en que pueda ser rentable una Investigación de Desarrollo española, especialmente con vistas al equilibrio de la balanza comercial en lo que a Tecnología se refiere.

Por supuesto, la Investigación de Desarrollo, en sí misma, encuentra en la Gran Empresa el clima apropiado, lo mismo que la Investigación Básica tiende a ubicarse en la Universidad.

Por lo tanto, nuestro Centro de Investigación no debe dedicarse, como tarea normal, ni a la una ni a la otra modalidad de Investigación, sino que han de permanecer centrados, con preferencia, en la Investigación Técnica, dispuestos siempre a cooperar en Investigaciones de Desarrollo, proporcionando técnicas de experimentación, poniendo a punto ensayos, suministrando información, colaborando en la programación y ejerciendo los controles de calidad. Pero la Investigación en sí misma, es decir, el peso fundamental de la Investigación de Desarrollo debe llevarlo la gran empresa, que es, en última instancia, la única entidad realmente capacitada para juzgar de su propia competitividad.

Madrid, 18 de junio de 1970. 